\title{
Medical Indemnity Insurance in the UK: a Public Choice Approach
}

\author{
by Roger Bowles and Philip Jones*
}

\section{Introduction}

Medical defence societies in the UK are non-profit bodies which provide medical practitioners with indemnity against the costs of actions for negligence. Subscriptions have risen very sharply in each of the past two years. While low compared with the costs of professional indemnity insurance for doctors in many other countries, the rapid increase has precipitated considerable concern within medical circles. An indication of the seriousness of the concern is that the medical defence societies themselves are contemplating making radical changes in their schemes. One medical defence society, the Medical Defence Union, has recently circulated a questionnaire to members inviting their views on a proposal to abandon the present flat rate indemnity premium in favour of a graduated scheme based on the practitioner's specialty. Another scheme which is currently attracting considerable attention in both the UK and the US would involve a move away from a negligence standard to a nofault approach to medical injury.

Our first concern in this paper is to offer a rationale for the structure of medical indemnity premiums in the UK at the moment. This entails a flat rate subscription, equal for all doctors, irrespective of medical specialty or previous claims experience. Exceptions to the rule relate only to a minority of practitioners who have recently qualified. By comparison, the standard model of market insurance provision has the insurer seeking to determine the premiums of potential customers on an individual basis. Characteristics which have proven to be reliable, and relatively cheap, indicators of likely claims under the policy are used to tailor the price charged to the expected cost of cover. Indeed to an extent this model appears to explain behaviour in the US. There, for example, premiums for medical malpractice insurance are geared to factors such as the state where the physician practises, size of practice and specialty (Quam et al, 1987). In the UK such considerations do not apply and the result appears quite perverse. It is known, for example, from the experience of the Medical Protection Society that doctors in the training grades make up $30 \%$ of membership but account for $40 \%$ of its payouts. ${ }^{1}$ This observations is itself important in that it suggests that a minority of potentially "risky" practitioners are able to attain a measure of subsidy via a flat rate premium.

\footnotetext{
* Senior Lecturer in Economics, University of Bath and Consultant to Centre for Socio-Legal Studies, Wolfson College, Oxford; Senior Lecturer in Economics, University of Bath.

${ }^{1}$ Quoted in Hospital Doctor, November 26, 1987, p. 1.
} 
The determination of practitioners' indemnity premiums will, of course, have important implications for consumers of medical care. The standard efficiency rationale for a negligence-based system of compensating victims of accidents is that, by imposing the costs generated by the potentially harmful activity on those who are engaging in it, the externalities can be internalised. The "general deterrence" argument, is articulated in contemporary guise by Calabresi (1979), Posner (1972), Brown (1973) and many others. The argument is that negligence rules will, at least on a number of specified assumptions, have the effect of inducing those engaging in activities which accidently harm others to take relevant precautions up to, but not beyond, the point at which the marginal cost of additional care is matched by savings in accidental losses. In markets for professional services such rules would make the careless professionals liable for losses which could have been avoided had reasonable care been exercised. Such is the potential scale of these losses that many professions make it a condition of practice that practitioners hold liability insurance. This has the advantage of assuring prospective buyers of services of recovery in the event of loss and of protecting practitioners from the prospect of bankruptcy. It has the disadvantage, however, of weakening the link between income and the care exercised, thus creating moral hazard. In the extreme case, where the size of premium payable is made independent of the likelihood of causing loss, this hazard will be at its greatest and the general deterrence properties of tort will be negligible. ${ }^{2}$

An evaluation of negligence thus becomes a matter of identifying its costs relative to its benefits. It seems to be widely conceded that negligence systems are costly to administer, because of the high legal costs associated with determination and quantification of liability. The proponents of the approach claim, however, that it has important deterrent powers which can too easily be overlooked, particularly by analyses which focus on the capacity of negligence to provide compensation consistently and fairly to victims. A reasonably representative statement of this position is to be found in Schwartz and Komesar (1978). They argue (at p. 1282) that: "By finding fault and assessing damages against the negligent provider, the system sends all providers a signal that discourages future carelessness and reduces future damages". A recent echo of this argument is to be found in Shavell (1987) when he notes (at p. 297) that: “... the liability system ... creates incentives toward safety. This, then, must be said to be the chief purpose of the liability system today". Yet with reference to medical negligence Schwartz and Komesar (1978) note that: "The lack of individual experience rating in malpractice premiums has, in the past, been economically acceptable to both the insurance industry and the medical profession" (p. 1287). This absence must be called in question to the extent that it will attenuate the incentive signals which are supposed to be the raison d'être of the negligence rules. Whilst neurosurgeons may, for example, be much more prone to being sued successfully for damages than, say, dermatologists, if the

2 This is not to say that professionals will act recklessly in such circumstances. There may be other control devices. Peer pressure, the desire to maintain a reputation for care and a wish to avoid being "dragged through the courts" or reported to professional disciplinary committees may all be relatively powerful sanctions operating to encourage doctors to exercise care. In practice, negligence very often operates alongside other institutions which have comparable objectives such as providing incentives to take care and providing compensation to accident victims. Social insurance and first party private accident insurance are obvious examples of the latter, and the control devices outlined in the previous paragraph are an example of the former. What is at issue, therefore, is the degree to which a negligence approach can complement these other sanctions. 
individual neurosurgeon is confident that his indemnity premiums will be unaffected even if his record is comparatively poor then the incentive to practice carefully may, at the margin, be reduced. ${ }^{3}$

\section{Collective choice and indemnity insurance premiums for the UK medical profession}

A brief sketch of the main features of the medical indemnity position in the UK is necessary in order to introduce a theoretical discussion. For medical practitioners in the $\mathrm{UK}$, insurance cover against claims for medical negligence is compulsory. The great majority of doctors insure with one or other of two long established firms, viz Medical Defence Union (hereafter MDU) and Medical Protection Society (MPS). The behaviour of these organizations with respect to the provision of insurance is very similar. They are non-profit making bodies and, as well as providing medical idemnity insurance, they offer their members a wide range of advice on matters such as good practice and how to handle claims. Indemnity insurance premiums are charged at a flat rate by both bodies with no regard to medical specialty or previous claims experience. Discounts against the standard premium are, however, offered to newly qualified doctors according to the schedule set out in Table 1 . With regard to this latter observation it may be noted that they apply to a minority of the profession.

Table 1

Medical rates of subscription in the United Kingdom 1987 and 1988

\begin{tabular}{lrr} 
& \multicolumn{2}{c}{ Rates (£) } \\
& 1987 & 1988 \\
\cline { 2 - 3 } $\begin{array}{l}\text { Full rate } \\
\begin{array}{l}\text { Concessionary rates to members who join } \\
\text { within three months of qualification: }\end{array}\end{array}$ & 1080 \\
1st year & 576 & \\
2nd year & 132 & 180 \\
3rd year & 210 & 240 \\
4th year & 264 & 396 \\
5th year & 318 & 492 \\
6th year & 396 & 600 \\
non-clinical membership & 120 & 744 \\
\end{tabular}

(Source : British Medical Journal, Vol. 295, 29th August 1987, p. 560 and Medical Protection Society).

The great majority of doctors in the UK are employed by the National Health Service. For hospital doctors this means, inter alia, that salary depends on experience and rank and is independent of specialty. The NHS as an employer requires these doctors to have indemnity insurance. The premiums, which are paid by the doctors, are tax-deductible. However,

\footnotetext{
${ }^{3}$ From the insurance company's point of view, the argument here would presumably be that the costs of assembling the relevant risk assessments ex ante by reference to anything more specific than specialty are prohibitive.
} 
in the pay settlement reached with the doctors in 1987 there was, for the first time, an explicit allowance made for the fact that premiums had risen sharply (British Medical Journal, 1987). For general practitioners (who in the UK tend to do little by way of surgery) indemnity insurance premiums are recoverable as an expense of the practice.

The apparent absence of market competition and the dominance of two medical defence societies, as described above, suggests that collective approval may be more important than the market in determining the price of insurance. It has been noted that defence societies are currently canvassing opinion on the question of how insurance premiums should be structured. Certainly amongst sections of the profession it appears important to have representation on the decision-taking committees within the insurance agencies. ${ }^{4}$ That such an outcome should have emerged is itself an interesting phenomenon. Here, however, we take such a situation as given and suggest an analysis of voting behaviour and political pressure which can predict the likely effects of collective choice on the premium structure of professional insurance. The key question is whether, or to what degree, we would expect to find support for a suggestion that practitioners in riskier specialties be subject to higher premiums.

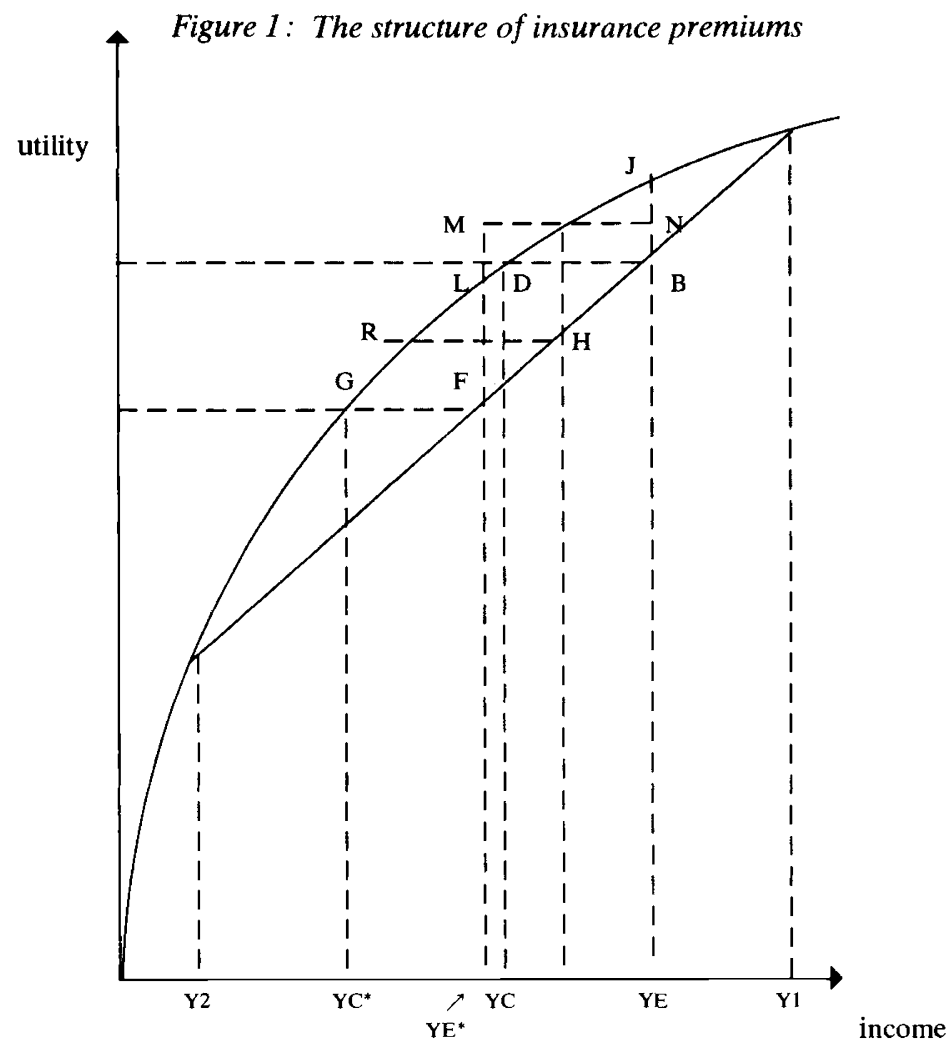

${ }^{4}$ See, for example, Hospital Doctor, November 26, 1987. 
Making the conventional assumption that individuals have marginal utility in income which is diminishing, albeit it at an increasing rate, we can illustrate, as in Figure 1, the utility function of a representative doctor. Let us assume that the doctor (in a given specialty) has initial income $Y 1$ but runs a probability $p$ of losing $(Y 1-Y 2)$ as a result of a successful suit for negligence. His expected income $((1-p) Y 1+p Y 2)$ we denote $Y E$. Our assumptions about the utility of income mean that the individual would be prepared to pay an amount $(Y E-Y C)$ in excess of an actuarially fair premium in order to avoid this risk. An insurance company in a monopoly position could expect to extract this excess in the form of profit, whilst in a competitive market (again ignoring costs other than claims) it would be reasonable to expect a premium of $(Y 1-Y E)$ to be charged.

Figure 1 also enables a comparison to be made of the position of two doctors with similar basic incomes (and utility functions) practising in different medical specialties. In the first specialty the nature of treatment is such that expected income is given by $Y E$, as defined in the previous paragraph, the certainty equivalent being $Y C$. The probability $\left(p^{*}\right)$ of a fall in income is much greater in the second specialty, although the extent of the fall in the event of a suit is the same, giving expected income $Y E^{*}$ with a certainty equivalent $Y C^{*}$. An insurance company with monopoly power setting individual rates for doctors in each speciality could charge doctor 1 a premium $(Y 1-Y C)$ and doctor $2\left(Y 1-Y C^{*}\right)$, making profits of $(Y E-Y C)$ plus $\left(Y E^{*}-Y C^{*}\right)$. The competitive firm would charge premiums of $(Y 1-Y E)$ and $\left(Y 1-Y E^{*}\right)$ respectively.

Suppose now that the insurance company were to ignore any disincentive effects and were to be constrained to pool the risks and set the same premium for each doctor. In order to identify the flat-rate premium chosen we would need to make further assumptions concerning market power and the objective of the insurance company. A competitive firm would find it difficult to agree to such a scheme; it would require some assurance that it would get an even mix of high and low risk practitioners or it would stand to lose if the riskier types were over-represented. A monopolist would be more likely to proceed if it is known that insurance is compulsory for all practitioners, since the price he would charge will most likely entail setting a flat-rate premium in excess of the amount that the safer of the practitioners was prepared to pay under the differential scheme. Provided that the monopolist knows that insurance is compulsory and has the expectation of an even mix of more risky and less risky customers, then assuming that it is profit maximizing, we might expect it to proceed by calculating the average expected payment of claims per insured, which will be $\left((Y 1-Y E)+\left(Y 1-Y E^{*}\right)\right) / 2$, and charging the certainty equivalent, giving a total premium comprising the average payout plus the distance $H R$ on Figure 1.

An alternative reference solution, with particular relevance for our purposes in this paper, is the premium which a non-profit company with some monopoly power might choose. In Figure 1 we assume that the non-profit company expecting equal numbers of high and low risk customers would calculate its average payment of claims to be ((YI-YE) $\left.+\left(Y 1-Y E^{*}\right)\right) / 2$, as in the previous case, requiring, to break even, a premium of exactly that size. In Figure 1 this is represented by the distance from $Y 1$ to the midpoint between $B$ and $F$, which we label $H$. Two points concerning collective choice are immediately obvious. First, the diminishing marginal utility assumption ensures that the loss of utility for the doctor in the safer specialty when he accepts a flat rate premium (measured in Figure 1 by the distance $J N$ ) is less than the gain in utility to the doctor in the riskier specialty (measured by $L M$ ) if we use the competitive solution at points $B$ and $F$ as the basis for comparison. 
The consequence of this is that on average there is greater resistance to selective insurance premium rates and greater support for a flat rate. 'To the extent that voter turnout is dependent on the gains associated with the electoral issue it would, at this stage, be reasonable to suppose that, on average, more of the risky practitioners will turn out to support a move to a flat rate scheme. With a simple majority voting rule $(50$ per cent +1$)$ the implication is that, ceteris paribus, the profession will collectively choose a flat rate schedule which is independent of specialty.

The second implication of the analysis relates to the amount of profit insurance companies could expect to earn if they were to maximise profits. The risk premiums (the amounts that individuals will pay in excess of the expected value of the loss) doctors are prepared to pay under a selective insurance premium amount to $[B D+F G]$, compared with $2 H R$ under a flat rate. Given the assumptions which underlie the utility function, $2 H R>[B D+F G]$, so that the profit for profit maximising insurance companies would be greater as a result of the collective decision to vote for a flat rate premium. Collective decision making (simple majority voting), in this way operates to distribute income away from the profession as a whole. Moreover, to the extent that an intermediary can operate between doctors and insurance companies, there is an economic rent to be earned by such an agent offering to provide "block" insurance cover at "flat" rate average premiums. ${ }^{5}$ This consideration may be relevant to the question of movement to a no-fault scheme.

Figure 1 also offers some insight on the question of why a section of the profession may remain "exploited" by a flat rate premium. The less risky are clearly paying "too high" a price by reference to market conditions and to this extent are "exploited". Why then does not a "specialist" insurance agency provide insurance exclusively to this group? If the specialist association were profit maximising and interpreted their specialist position as affording monopoly power they may charge a premium of $Y I-Y E$ plus the certainty equivalent $B D$. The price they would set (inclusive of the certainty equivalent) would not undercut the price charged by a non-profit organization to the "exploited" group because the nonprofit organization offers the actuarially fair price. (In fact in the example shown the price to the safe practitioner is less with the non-profit organization than with a profit maximizing specialist agency and the utility gain in dealing with the former is still positive, i.e. $N B$ ). Alternatively if the "set up" costs were higher for a more competitive specialist association, it may still have difficulty undercutting the non-profit professional association. For either reason the "exploitation" (within margins) may be predicted to persist because medical defense societies are non-profit associations. While this explanation is speculative it is another facet of the analysis which would rationalise the continued existence of the flat rate premium.

\section{The "tyranny" of the minority}

Thus far we have ignored the question of the balance within the medical profession as between practitioners posing different degrees of risk on the insurance scheme. The choice between a flat rate and a graduated scale might be expected to depend, to some degree, on

${ }^{5}$ In the UK this has not been an issue in the medical indemnity field, but it was an important criticism in the early days of the Law Society's Master Policy under which the Law Society earned for itself a hefty commission whilst providing compulsory indemnity insurance for solicitors. 
the distribution of practitioners across risk classes. In order to explore this question more carefully, we develop a simple model which can be used to determine the voting behaviour to be expected as the relative size of a risky subset of the population is varied. This is obviously only a first step because we limit the analysis to just two groups of practitioners and continue to make strong assumptions about identical utility functions, aversion to risk and so on. The results we get are nevertheless different from those which conventional models of pressure groups produce, since we are able to predict that minority preferences will sometimes win the day. This has important implications for the analysis of professional indemnity insurance schemes, particularly in cases where some small groups may stand to gain or lose disproportionately large amounts.

Let us suppose that there are two groups of doctors, a high income group who earn $Y$ and a second group who practise a risky specialty in which the average practitioner stands to incur damage costs of $(Y-X)$, leaving net income equal to $X$. We will denote by $b$ the fraction of doctors who belong to the risky group. This fraction $b$ can equivalently be thought of as the size of the flat rate premium that would be required to maintain a selffinancing insurance scheme, since the expected loss the scheme has to cover (loss per claim times the expected frequency of claims, $(Y-X) b)$ must be covered by premium income (ie the average premium paid, $b(Y-X))$. We could equally well think of the scenario as one in which the income levels $X$ and $Y$ have both already been adjusted for an insurance premium, with the difference $(Y-X)$ representing the size of the differential between premiums in a graduated scheme.

Fig. 2: The geometry of gains and losses from a move to flat-rate premiums

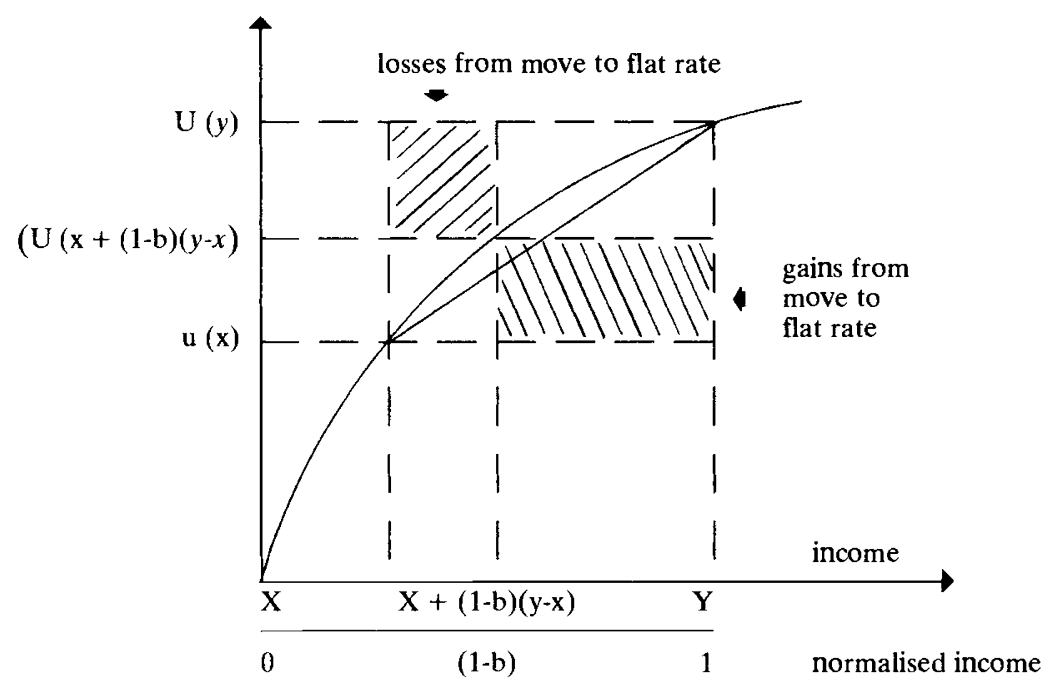


Figure 2 outlines the starting position. It will be obvious that as the relative size, $b$, of the risky group increases expected income falls and the flat rate premium that would be required to finance the scheme increases. Now, with risk neutrality, we would expect a majority to prefer the flat rate scheme if and only if the majority belonged to the risky group, for only in these circumstances would we find there being a numerical majority standing to gain. With our assumption of risk aversion this result has to be modified if we are also going to allow the size of prospective gains and losses to influence the propensity to participate in a vote.

Using as a starting point a solution in which the risky group pay a premium equal to expected damage costs and the other group pay zero, we consider the response to a proposal that a flat rate premium of size $b(Y-X)$ be applied to all doctors. For the risky group, this represents a gain in utility terms of $[U(X+(I-b)(Y-X))-U(X)]$. For the other group, the net loss is $[U(Y)-U(X+(1-b)(Y-X))]$, where $U(Y)$ represents their initial utility level.

We make the propensity to vote proportional to the utility gains and losses, the factor of proportionality being $z$, so that the fraction voting in favour, $v$, can be written:

$$
v=b z[U(X+(1-b)(Y-X))-U(X)]
$$

and the fraction voting against, $w$, can be written:

$$
w=(1-b) z[U(y)-U(X+(1-b)(Y-X))]
$$

It is convenient at this point to normalise the income scale, setting $X=O$ and $Y=1$ with the result that the premium becomes $b$. The fraction, $f$, voting in favour of a flat rate scheme, defined as $v$ less $w$, now becomes:

$$
\begin{aligned}
f & =v-w=b U(1-b)-[1-b][U(1)-U(1-b)] \\
\Rightarrow & f=b U(1-b)-\{U(1)-b U(1)-U(1-b)+b U(1-b)\} \\
\Rightarrow & f=-U(1)+b U(1)+U(1-b)
\end{aligned}
$$

Now, for the vote to run in favour, this fraction must be positive, requiring:

$$
U(1-b)>U(1)-b U(1)
$$

Intriguingly, this conditions is satisfied for all $0<b<1$ by the concavity of $U($.$) , as inspec-$ tion of Figure 2 which graphs it will immediately reveal. This implies that the vote will always go in favour of the flat rate scheme irrespective of the size of the risky group or the intensity of risk aversion. Casual inspection of Figure 2 will reveal an intuitive proof. Losses under the move are given by the product of the number of losers $[1-b]$ and the size of loss $\{U(1)-U(1-b)\}$, this being represented by the shaded rectangle in the top left hand side of Figure 2. Gains are represented by the bottom right hand rectangle in the diagram with sides $b$ and $U(1-b)-U(0)=U(1-b)$. Subtracting losses from gains will always leave a positive net gain provided that the utility function is concave. With risk neutrality we would find 
gains always matching losses exactly since, as elementary trigonometry will show, the areas of the two rectangles will remain equal in size as the value of $b$ is varied. ${ }^{6}$ With the risk aversion the lower rectangle is always larger than the upper left one. ${ }^{7}$

6 The proof refers to Figure 3 below. Construct a rectangle with unit length on the horizontal $x$ axis, and height $k$. Consider any point, such as $D$, with coordinates $(x, k x$; where $0<x<1)$ on the diagonal. Construct two further rectangles like $A B C D$ and $D E F G$ with point $D$ in common. The former has area $[1-x] . k x$ and the latter has area $x .[k-k x]$. These two areas are equal. $Q E D$.

Fig. 3: Measuring gains and losses in move form differential to flat-rate premiums

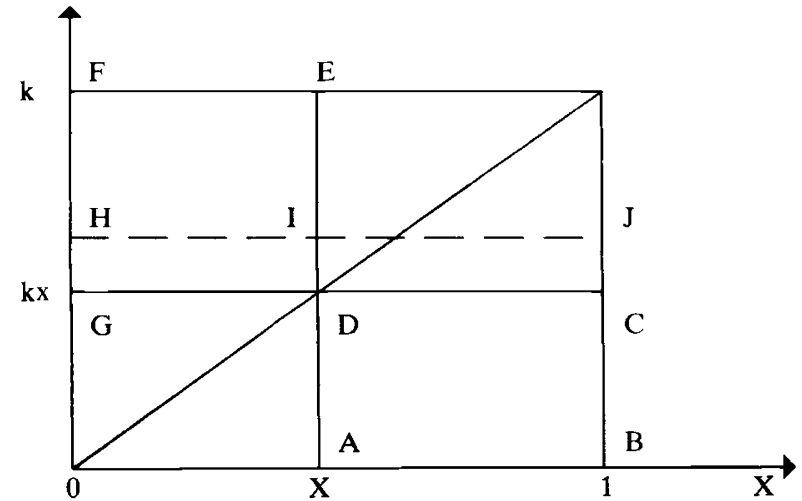

7 With risk aversion, the coordinates of the point common to the two rectangles are $(x, k x+d y)$ so that the relevant rectangles are now $A B J I$ and $I E F H$. It follows by inspection that the area of $I E F H$ is less than the area $A B J I$. $Q E D$. It is of interest also to note that this result survives, at least to some degree, when we complicate the picture by allowing there to be more than two risk classes. For example, with a distribution of losses across practitioners which is rectangular on an interval $[0,(Y-$ $X)]$, mean loss is given by $(X+Y) / 2$. In terms of utility gains and losses the intuition is that the utility losses to the $50 \%$ of practitioners who lose under a switch from risk-related to a flat-rate premium will be less than the utility gains to the remaining $50 \%$. This can be readily illustrated as in Figure 4 . The flat-rate premium becomes $[X+Y] / 2$ implying (inter alia) a utility loss of $\{U(Y)-U(X+Y] / 2)\}$ for the safest practitioner and a gain of $U([X+Y] / 2)$ for the riskiest. The gains are readily seen to be the area under the utility of wealth schedule over the range $[0,[X+Y] / 2]$. The losses are measured by the area enclosed by EDF, ensuring with a concave utility function that net gains will be positive. $Q E D$.

Fig. 4: Gains and losses from a flat rate schedule with a uniform loss distribution

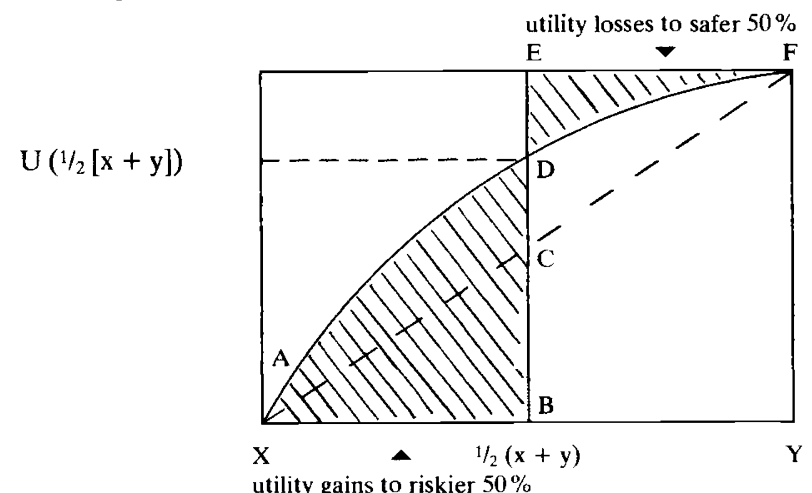


The very powerful implications we have just outlined appear "too strong", for it would not seem plausible that $1 \%$ of risky practitioners could expect to wiri a vote in favour of a proposal that their losses be subsidised by the remaining $99 \%$ of safe practitioners. ${ }^{8}$ And yet that is what the theory is saying: each member of the $1 \%$ has a great deal at stake whilst the remainder each stand to pay such a relatively small sum if they lose, that they don't bother to turn out to vote. To consider this possibility it is necessary to introduce the costs of political action.

Both voting and lobbying are activities which entail, at minimum, non-pecuniary costs of time and effort (Downs, 1957). The decision to become involved in such activities must depend on the net expected utility associated with such activity. The choice will be between the expected gain associated with political action and the certainty reference point. In each case, assuming individuals are cautious or pessimistic the reference point will be the worst that can happen if they do not engage in political activity. For the risky practitioner the reference point will be experience rating. A move to experience rating reduces his (net of insurance premium) income as under this proposal he will be charged a greater premium. The certain reference point for the safe practitioner will be the reduction of his income by an average flat rate premium. In the worst event for the safe practitioner his income will be higher than in the worst event for the riskier practitioner. The reference points are, therefore, not the same and, if the marginal utility of income diminishes at an increasing rate, the certain utility losses associated with political action for a risky practitioner are likely to be greater than those for a safe practitioner. This asymmetry in the utility losses associated with the costs of political action may well affect turnout from each group, favouring potential losers from the introduction of a flat rate scheme. On the other hand, as the minority becomes smaller, the probability that they can attach to the prospect that their involvement in political action will have any effect on the result must fall. In terms of straightforward majority voting the prospects of the minority winning are reduced even if each member of the minority believes that all of the minority will turn out. For this reason, as the minority falls, there may arise a point at which any member of the minority would refuse the gamble implied by engaging in costly political action. As such, there may exist both upper and lower bounds on the size of a tyrannical minority which are dependent on the costs of voting and the probability of successful political action.

Further assumptions would have to be introduced to establish these bounds. It is, however, clear that, when each member of a minority gains from a flat rate insurance premium, these gains, in aggregate, exceed the sum of the losses to the losers. A prima facie case exists for supposing that with the assumptions applied here a risky minority of the medical profession may attain subsidy for indemnity insurance via a collective choice mechanism.

\section{The implications of collective choice for the medical indemnity debate and for the consumer of medical care}

The above analysis appears consistent with experience within the UK medical profession. Not only do we find a flat rate premium structure but we also find, as Table 1 indicates, "younger" members (who constitute only a minority of the profession) enjoying an

${ }^{8}$ From a welfare perspective we are concerned here with net gains which could represent a HicksKaldor improvement, but not a Pareto improvement. 
advantageous position, at least in actuarial terms. The premiums they pay are almost certainly below the level which their likely claims would indicate, and are in any event below the average paid by practitioners as a whole. Whilst not suggesting that such casual empirical evidence is in any way conclusive, it is at least consistent with our collective choice analysis. Moreover, the same analysis can be applied to explain recent, though different, insurance premium experience in the law profession.

With reference to the current medical debate and the likely outcome of the vote currently being conducted by the MDU on whether practitioners would approve the adoption of differential subscriptions, the accepted literature on the tyranny of the majority would suggest that a majority of gainers from a vote would impose costs on a minority even if each gainer gained less than each loser lost (Buchanan and Tullock, 1969). The usual voting model would suggest that a majority would vote in favour of a move away from a flat rate premium. Our analysis has introduced the possibility that precisely the opposite result may occur. It can be envisaged that a minority of potential gainers may have a greater incentive to retain the status quo and oppose the change and therefore may turn out in greater proportions. Clearly it is necessary to bear in mind that turnout rates (and thus differences in turnout rates) will be sensitive to the precise structure of gains and losses to be anticipated under the proposal. Moreover, we would want to identify a number of other factors likely to have an influence on the outcome of the current debate:

(1) General practitioners do not themselves pay the premium. These expenses of running a practice are met by the government. Hence one might expect a relatively low participation rate from this (relatively safe) group.

(2) If experience related premiums were to lead to changes in the pay structure of the profession this might prompt a fear of a threat to "clinical freedom" and to a more active involvement of health administrators in areas traditionally regarded as the preserve of medical practitioners. This would, if anything, be likely to bias the outcome in favour of the status quo.

(3) There are probably non-economic elements at work. For example, arguments about loyalties to one's professional colleagues most exposed to negligence claims might influence doctors to vote in favour of a flat rate scheme, even where their own financial interests would be adversely affected as a result. Moreover, junior hospital doctors, it is widely recognised, work long hours for modest immediate returns, and many of their colleagues may altruistically feel reluctant to force a heavy loading of premiums for those in this group.

(4) The doctors responding to the questionnaire have very little hard evidence (although no lack of anecdotes from the US) as to the likely premium structure which differential rates would entail. Insufficient information to infer a prognosis for the premium structure with differential premiums may result in a poor turn out or a vote in favour of the (known) status quo.

(5) The medical defence societies, while receptive to professional opinion, are not in any event committing themselves to change, even if the doctors vote in favour of a differential scheme. The incentive to participate may therefore be affected.

(6) One danger which many doctors already identify is the increasingly attractive position occupied by general practitioners relative to hospital doctors. Numbers of GP's have been expanding rapidly in recent years, and any move to make indemnity premiums risk-related would tend to intensify the relative attractiveness of general practice. This would probably 
be regarded as a potentially harmful development by both hospital doctors (who would find themselves under increasing pressure) and by GP's themselves who might perceive this as a threat to list size, and thus to income levels.

In summary then the question is in practice a broader and more complex one than the model of section 3 above allows. Yet the prospect that a minority of the profession can have, and indeed manifestly have had, a significant influence on the structure of insurance premiums is of importance. From society's perspective the key concern is the degree to which there exist adequate safeguards to help ensure that the interests of patients are fully reflected in the physician's calculus. The capacity of a negligence action to bring about full internalisation of the costs of harm is relatively easily subverted. Such subversion may result from the existence of high costs of screening individual practitioners for purposes of assessing risk and thus setting premiums, but it may also result if powerful minorities are able to use voting or lobbying to bring about rearrangements within the premium structure.

The premium schedule for the UK clearly appears to subsidize risky specialties and, within specialties, risky practitioners. Bendan Devlin, consultant surgeon at North Tees General Hospital has made a study of surgeons' mistakes and he notes that "juniors are more likely to make bad decisions...". Similarly it was reported that " 1,000 people in Britain die each year as a result of surgical errors. Some of the mistakes occurred because... junior doctors were more likely to make bad decisions...". ${ }^{9}$ However, above it is "younger" junior hospital doctors who experience explicit concessional insurance premiums in the UK and other juniors who may experience implicitly subsidized insurance premiums.

The absence of an experience related scheme cannot easily be defended in terms of the "policing" role of professional associations. It is not sufficient to look to the General Medical Council as a satisfactory alternative mechanism for maintenance of professional standards of medical care. ${ }^{10}$ The other influence on medical practice in the UK is, of course, the National Health Service. However, as an institution, the NHS appears also to have vested interests in the maintenance of this system. It is well known that junior hospital doctors are a cheap source of labor. ${ }^{11}$ To the extent that more risky junior staff are subsidized by less risky, more experienced, staff the insurance costs of junior doctors are reduced. It is arguable in the light of recent negotiations, that the NHS would be faced with an increase in salary payments for junior hospital doctors were these junior doctors charged more "realistic" insurance premiums.

The general concern raised in this paper is that, when producer groups are freed from the discipline of the market (whether a market for their services or a market in which they buy indemnity insurance) standards of service may be threatened. This conclusion is signifi-

${ }^{9}$ Quoted in The Independent, 7 January 1988, p. 1.

${ }^{10}$ Lees $(1966$, p. 30$)$ notes that : "Professional claims to be custodians of consumer welfare would cut more ice if their associations expelled members for incompetence. But they do not do so, preferring to act like any club by protecting their own. It is difficult, for example, for the plaintiff to get a doctor to testify against the defendant in cases of medical negligence."

Klein $(1973$, p. 170) notes that "if it is the function of the courts to deal with the doctor who damages his patient, it is the function of the General Medical Council to deal with the doctor who damages his own profession".

${ }^{11}$ Indeed in the USA they similarly have always played an essential role in mitigating the costs of hospitals (Kessel, 1958). 
cant in terms of the debate as to whether or not the current system should be replaced by a no-fault scheme. To the extent that the costs of insurance in a no-fault scheme are passed from producers to government taxation, it is reasonable to suppose that each section of the profession would have an incentive collectively to support such a move. ${ }^{12}$ The introduction of such a scheme may be considered yet a further move away from experience rated premiums; predictable from an analysis of collective choice but of concern in the context of patient care. The NHS may perceive some advantage in assuming the no-fault scheme for, while assuming the costs associated with the negligence of doctors, it also may internalise the economic rents associated with the monopoly provision of insurance on a collective choice basis. Of course these vested interests will argue that this is to the advantage of the patient, in so far as the patient may achieve more speedy and predictable redress for the losses they experience. Our concern, however, would be that the no-fault scheme potentially insulates doctors even further from the effects of professional negligence. The incentive mechanism that might be associated with experience related fees are further lost with potential detriment to patients. Collectively the profession will achieve even further insulation for practitioners; an insulation traditionally guarded in the context of "clinical freedom".

\section{Conclusions}

The first objective of this paper was to explain the current structure of premiums for professional indemnity in the context of a public choice analysis. It has been argued that, to the extent that collective responsibility for premiums is shared by practitioners with a degree of monopoly power, the structure of premiums will reflect the interests of those more prepared to incur the costs of political influence. Within an insurance framework this implied that a minority of relatively risky practitioners may succeed in transferring their insurance costs to the safer section of the profession. In public choice literature the potential "tyranny" of the majority has long been presented as a critique of majority voting and democracy (de Tocqueville, 1835). Here we have established that in determining the structure of insurance premiums by collective choice the minority can prove tyrannical. Moreover, this is shown to arise not because of ignorance on the part of the majority but because the issue means more to each member of the minority than to each member of the majority.

The second objective was to comment on the implications for the provision of medical care. Here we have argued that the consumer has reason for concern as to the current medical debate. In particular, a movement toward no-fault and potentially even further from experience rating, must incorporate adequate safeguard for the consumer, even if at the cost of the principle of "clinical freedom".

12 The British Medical Association and the medical defence societies both expressing themselves in favour of such a development (Warden, 1987; MDU, 1987). 


\section{REFERENCES}

British Medical Journal (1987) Medical News: Defence dues breach $£ 1000$ barrier, 295, 560.

BROWN, J. P. (1973) Towards an Economic Theory of Liability, J of Leg Studs, 2.

BUCHANAN and TULLOCK (1969) The Calculus of Consent, Ann Arbor: Univ of Michigan Press.

CALABRESI, G. (1970) Costs of Accidents, New Haven: Yale Univ Press.

de TOQUEVILLE A. (1835) Democracy in America, Reprint Edition, Oxford: Oxford University Press.

DIAMOND, P. (1974) Accident Law and Resource Allocation, Bell J of Econ and Man Sci, 5, 366-406.

JONES M. A. (1987) Medical Injury - the fault with no-fault, Professional Negligence, May/June.

KESSEL R. (1958) Price discrimination in medicine, Journal of Law and Economics, October.

KLEIN R. (1973) Complaints Against Doctors, London: Charles Knight.

LEES D. S. (1966) Economic Consequences of the Professions, Research Monograph 2, London : Institute of Economic Affairs.

POSNER R. (1972) A Theory of Negligence, J of Leg Studs, 1.

QUAM L., DINGWALL R. and FENN P. (1987) Medical Malpractice in Perspective: I - The American Experience and II - The Implications for Britain, Br Med J, 294, 1529-32 and 1597-1600.

SCHWARTZ W.B. and KOMESAR N.K. (1978) Doctors, Damages and Deterrence: An Economic View of Medical Malpractice, New Engl J of Med, 298, 1282-1289.

SHAVELL S. (1987) Economic Analysis of Accident Law, Cambridge, Mass, Harvard Univ Press.

WARDEN J. (1987) Damages Unlimited, Brit Med J, 295, 280. 